WIENER SLAVISTISCHES JAHRBUCH, Band 54/2008, 21-46

(C) 2008 by Österreichische Akademie der Wissenschaften, Wien

PETER DEUTSCHMANN

\title{
Historische Repräsentation im Wandel. Tschechische und russische historische Dramen in der Moderne ${ }^{1}$
}

I. Der Gattung Drama sind zeitliche Paradoxa eingeschrieben: Die Rahmenbedingungen des Mediums Theater, das vorab verfasste Texte inszeniert, um dem versammelten Publikum eine Ereignisabfolge aktualiter vorzuführen, sind schon für das Drama selbst prägend. Die vom Dramentext tradierten Ereignisse sollen den aktuellen Moment der Rezeption mit den vergangenen Momenten des Textes - der Situation seiner Niederschrift, der Zeit, in welcher die Handlung angesetzt ist - verbinden. Die reale Zeit der Rezeption und die fiktive bzw. dargestellte Zeit laufen parallel nebeneinander her, woraus sich die scheinbar unmittelbare „Gegenwärtigkeit des dargestellten Geschehens“ ergibt, die in der „Gleichzeitigkeit des Dargestellten mit der Darstellung und dem Vorgang der Rezeption“ (Pfister 2001: 23) besteht. Ein Dramatiker kann das Raum-Zeit-Kontinuum als grundlegendes Gattungsmoment allenfalls als Normen- oder Traditionsbruch verändern (selbst dabei bleibt freilich der „Echtzeit"-Charakter dramatischer Rede irreduzibel), während er bei der Auswahl des „Settings“ der Handlung (Ort und Zeit) weitgehend freie Hand hat, diese also semiotisch signifikant ist.

Die Darstellung „historischer“ Stoffe in Dramen macht diese Paradoxie besonders deutlich, da hierbei ein Gegensatz zwischen der Vergangenheit des Stoffs und der Aktualität der Rezeption sowie der Offenheit der Handlungsentwicklung empfunden werden kann, womit das ,historische Spiel“ „undramatisch“ zu werden droht (so apodiktisch Szondi 1978: 18; vgl. dazu auch Paul 1974: 13 ff.).

${ }^{1}$ Die Beschäftigung mit der in diesem Aufsatz thematisierten Literatur wurde entscheidend durch einen von der Österreichischen Forschungsgemeinschaft finanzierten MOEL-plusAufenthalt in Prag 2006 befördert. 
Nicht allein der Gegensatz zwischen dem historischen Stoff und der Gegenwart der Rezeption macht jedoch das zeitliche Paradoxon des historischen Dramas aus, sondern auch dessen Relation zur Gegenwart seiner Entstehung: In der Darstellung geschichtlicher Ereignisse manifestieren sich aktuelle Probleme und Fragestellungen (vgl. Lindenberger 1975: 5). Gleichsam normativ wurde dies bereits von Hegel festgelegt, in dessen geschichtsphilosophisch argumentierenden Vorlesungen über die Ästhetik vom Dramatiker gefordert wird, nicht akribisch auf historische Authentizität abzuzielen, sondern um der Wirkung auf das je gegenwärtige Publikum willen nur die überzeitlichen und allgemeinen Momente des dramatischen Stoffes dichterisch herauszuarbeiten. Von einem für die Kunst „notwendigen Anachronismus“ sprechend meint Hegel:

Werden daher fremde dramatische Werke in Szene gesetzt, so hat jedes Volk ein Recht, Umarbeitungen zu verlangen. Auch das Vortrefflichste bedarf in dieser Rücksicht einer Umarbeitung. Man könnte zwar sagen, das eigentlich Vortreffliche müsse für alle Zeiten vortrefflich sein, aber das Kunstwerk hat auch eine zeitliche, sterbliche Seite, und diese ist es, mit welcher eine Änderung vorzunehmen ist. Denn das Schöne erscheint für andere, und diejenigen, für welche es zur Erscheinung gebracht wird, müssen in dieser äußeren Seite der Erscheinung zu Hause sein können. In dieser Aneignung nun findet alles dasjenige seinen Grund und seine Entschuldigung, was man in der Kunst Anachronismen zu nennen und den Künstlern gewöhnlich als einen großen Fehler anzurechnen pflegt. (Hegel 1986: 358)

Der vorliegende Beitrag nun wendet diese normative Aussage Hegels deduktiv, um die historische Aktualität von Geschichtsdramen ${ }^{2}$ zu akzentuieren, die zwischen ungefähr 1880 und 1930 entstanden sind. In diesen Zeitraum, der oft mit der Epochenbezeichnung „klassische Moderne“ versehen wird, fallen gravierende Veränderungen in der europäischen Kulturgeschichte, welche vielerlei „Reihen“ bzw. „Systeme" (Politik, Kunst, Technik, Recht, Medien ...) betreffen. Inwiefern manifestiert sich in Dramen, deren Handlung in einem historisch deutlich von der damaligen Gegenwart unterschiedenen Zeitraum angesetzt ist, die historische Situation des Autors bzw. seines zeitgenössischen Publikums, welche Veränderungen der soziopolitischen Verhältnisse haben wie ihren Niederschlag in der Gestaltung historischer Dramen gefunden? Der für diesen Zeitraum charakteristische und vielfach thematisierte Wechsel der „Ismen“, der mit scharfer Abgrenzung von der jeweiligen Generation der „Väter“ und Vorläufer verbunden war, findet in der Gattung des historischen Dramas keine deutliche Entsprechung. Zumal es sich immer um Repräsentationen von Geschichte handelt, unterscheiden sich Dramen von Autoren wie Jaroslav Vrchlický, Alois Jirásek oder Julius Zeyer, von denen sich die erste Generation der „Mo-

2 Die hier synonym verstandenen Ausdrücke „Geschichtsdrama“ und „historisches Drama“ haben in vorliegendem Beitrag eine große Extension, sie beziehen sich auf eine Menge von Theaterstücken, deren wichtigste Gemeinsamkeit darin besteht, dass in ihnen explizit Bezug auf historisch verbürgte Ereignisse gemacht wird. Dies verstehe ich als eine Minimaldefinition dieser dramatischen Subgattung, für die es keine umfassende Genredefinition geben kann (vgl. Pavlovský 2004: 114 f.) 
dernen“ 1895 per Manifest distanzierte, vorwiegend formal von historischen Dramen dezidiert „moderner“ Autoren wie Jaroslav Hilbert oder Viktor Dyk. Der Historismus der Moderne und der Avantgarde wurde - eher in der tschechischen als in der russischen Literaturgeschichtsschreibung - ob des Getöses der programmatischen Deklarationen lange übergangen, worauf Řezníková (2004) aufmerksam macht, die zwar auf das historische Drama in der Moderne verweist, es aber nicht weiter thematisiert. Untersucht man, wie hier vorgeschlagen wird, weniger die Form der Werke, sondern deren ideologischen Gehalt und dessen Bezug zur Entstehungszeit, werden die Unterschiede weniger auffällig als die Ähnlichkeiten zwischen einzelnen Dramen. Die zeitlichen Paradoxa des historischen Dramas bringen mit sich, dass die historischen Dramen als ,außer der Zeit“ stehend anmuten, dass dennoch dabei ein „anachronistischer“ Zeitbezug in ihnen zu erkennen ist.

Um die „Anachronismen“ der Stücke, die auch als „Panchronismen“ oder „Allochronismen" bezeichnet werden könnten, insofern sie ein überzeitliches, zumindest in der Entstehungszeit der Dramen aktuelles Problem betreffen, in einigen exemplarisch ausgewählten Werken aufzuzeigen, bedarf es kurzer methodischer Vorüberlegungen zum Verhältnis von (historischem) Drama, Geschichtsschreibung und realer Geschichte.

II. Die Relation von Geschichtsschreibung und Drama ist historischem Wandel unterworfen: zum einen brachte der Wandel des Geschichtsbewusstseins eine Unterscheidung von bloß mythisch-fiktiven und historischen Ereignissen mit sich, womit etwa Dramen der griechischen Antike, die für das damalige Publikum einen Bezug auf die Vorgeschichte hatten, ,unhistorische“ Fiktion wurden, zum anderen betrachtete das antike Publikum die wenigen Dramen, die auf historisch gut bekannten Begebenheiten rekurrierten - so etwa Der Fall Milets (494 v. Chr.) von Phrynichos oder Aischylos' Perser (472 v. Chr.) - mit großer Ablehnung (vgl. Kindermann 1966 ff.). Die römische Antike wiederum bevorzugte Stoffe mit geschichtlichem Bezug. Neuzeitliche Autoren wählten für Tragödien fiktive Stoffe oder historische Begebenheiten, die den Genrebedingungen angepasst wurden, ohne dass dabei im Genre Tragödie zwischen fiktionalen Welten und Faktenbezug kategorisch differenziert wurde. Entsprechend war gerade die Literaturwissenschaft lange darum bemüht, das historische Drama von der allgemeinen Gattung Drama aufgrund des Merkmals historisch beglaubigter Sachverhalte zu unterscheiden, was zur Folge hatte, dass diese Subgattung lange Zeit vorwiegend nach semantischen Kriterien bestimmt wurde. Historisch verbürgte, d. h. von der jeweils aktuellen Geschichtsschreibung beglaubigte Inhalte galten als das wesentliche Merkmal des historischen Dramas. Zumal die Regeln historiographischen Schreibens nicht für die Belletristik gelten und es folglich nur wenige Dramen gibt, in denen ausschließlich historisch tradierte Sachverhalte vorgeführt werden, sondern vielmehr historische Personen immer wieder mit fiktiven Personen interagieren, gilt das Genre als „hybrid“ (Nünning 1995: 35 f.). 
Diese Hybridität des historischen Dramas zwischen historischem Bezug und Fiktion findet eine diskursgeschichtliche Entsprechung im Umstand, dass im 19. Jahrhundert viele Autoren historischer Belletristik auch als Verfasser geschichtlicher Werke fungierten, Literatur und Geschichtsschreibung bei ihnen also in Personalunion verbunden war. ${ }^{3}$ Auch nach der Ausdifferenzierung von Historiographie und Belletristik, die relativ spät erfolgte (vgl. Hüttmann 2001: 15 ff.), bilden in der Regel immer noch historiographische Texte die Grundlage für das literarische Geschichtsdrama.

Hayden White unterscheidet in Metahistory (1973) mehrere Strata im Textaufbau historiographischer Werke. Auf einer elementaren Ebene ist dies die Umwandlung der Chronik (chronicle) in eine Fabel (story), nachdem schon zuvor eine Auswahl bestimmter Ereignisse als für eine Chronik relevanter erfolgt sein muss. Nach White (ebd.: 19 ff.) stellt die Fabel, die aus einer Chronik entstanden ist, eine einfach nacherzählte Geschichte dar, deren Anfang und Ende deutlich markiert ist. ${ }^{4}$ Aus der Fabel modelliert der Historiker dann eine Geschichte, die bedeutungsvoll ist und Erklärungen für die erzählten Ereignisse liefert. In diese Erklärungen fließen in rudimentärer Form literarische Gattungschemata bzw. diesen entsprechende Deutungsmuster ein. ${ }^{5}$ Neben den literarisch-historiographischen „Gattungen“ gibt es in Geschichtswerken freilich auch noch explizitere Erklärungsmuster (z. B. nomologisch-deduktive und diskursive), überdies können sich Historiker nicht von ihren ideologischen Standpunkten freimachen, nolens volens manifestieren sich auch diese in den von ihnen verfassten historiographischen Texten.

${ }^{3}$ Nikolaj Karamzin war Verfasser sentimentalistischer Erzählprosa und der Autor der monumentalen Istorija Gosudarstva Rossijskogo (1818-1829), welche Aleksandr Puškin für seinen Boris Godunov (1831), das paradigmatische historische Drama der russischen Literatur, konsultierte. Puškin selbst arbeitete bekanntlich an einer Biographie über Peter den Großen und verfasste mit der Istorija Pugačeva (1834) eine Fragment gebliebene Beschreibung des großen Bauernaufstands. Dem im Zuge des obrozeni geweckten Interesse für die tschechische Kultur und Geschichte wurde mit František Palackýs Geschichte von Böhmen (1836-1867) begegnet; Palacký versuchte sich in seiner Jugend auch als Dichter und steht somit in einer Reihe von Persönlichkeiten der tschechischen bzw. slowakischen Kulturgeschichte, die Literatur und Wissenschaft in ihrem Schaffen verbanden. Zu nennen wären neben Palacký Pavel Josef Šafař́í, František Čelakovský, Jan Nebeský, Jan Kollár, Josef Václav Sládek, Jaroslav Vrchlický, Jaroslav Goll, František Xaver Šalda, Arne Novák, Otokar Fischer (vgl. Schamschula 1996: 35 f.).

${ }^{4}$ Der bekannten narratologischen Unterscheidung von „Fabel“" und „Sujet“ ist mit der „Chronik“ also eine elementare Ebene vorgeschaltet, welche erst das relevante „Material“ für die narrativen Operationen liefert. Bekanntlich gehören in vielen Literaturen - so etwa der altrussischen - die Chroniken zu den ältesten Texten. Narrative Geschichtstexte folgen meist erst später.

5 Entsprechend seiner Hypothese, dass die Historiographie meist uneingestanden viel mit Rhetorik und Belletristik gemeinsam hat, unterscheidet White auf dieser dritten Ebene als Grundformen der geschichtswissenschaftlichen Erklärung „Romanze“, „Tragödie“, „Komödie" und „Satire“. 
Wenn der Geschichtsschreibung wie auch dem historischen Drama die Thematisierung von tatsächlichen Ereignissen gemeinsam ist, gilt es dennoch, die unterschiedlichen Modi dieser Thematisierung durch die beiden Gattungen zu betrachten. Fasst man die oben mit White beschriebenen Strata eines historiographischen Textes chronologisch auf, so ergibt dies folgende Reihe: (außertextuelle) Ereignisse $\rightarrow$ Chronik $\rightarrow$ Fabel $\rightarrow$ historiographisches Werk; die Genese eines Geschichtsdramas hingegen verläuft - vereinfacht gesehen - umgekehrt: es nimmt seinen Ausgang meist von einem historiographischen Text, in welchen die von White beschriebenen Faktoren gleichsam eingefaltet sind, um daraus wieder Ereignisse zu machen, die im Medium Text oder auf einer Bühne den Rezipienten vorgeführt werden.

Aufgrund dieses Transformationsprozesses - selbst wenn dieser hier nur theoretisch-abstrakt beschrieben ist, kann gelten, dass konkrete historische Dramen auf einem vergleichbaren Weg zustande kommen - hat man es mit zwei grundsätzlich differenten „historischen Ereignissen“ zu tun: den realen außertextlichen Ereignissen, welche von der Geschichtsschreibung transformiert werden, und den vom Text repräsentierten und ggf. in eine Inzenierung mündenden Ereignissen, deren ontologischer Status von den realen Ereignissen natürlich kategorial verschieden ist, handelt es sich doch um virtuelle bzw. um Quasi-Ereignisse, um Repräsentationen, deren Rezeption historische Vergangenheit gegenwärtig macht bzw. aktualisiert.

Die Eigentümlichkeit von Repräsentationen - historische Dramen, aber natürlich auch andere Genres und Darstellungen können als solche gelten - besteht darin, dass Repräsentationen im Unterschied zu realen Sachverhalten bzw. Ereignissen komplexer organisiert sind. Ankersmit (2002: 18 f.) erläutert dies am Beispiel eines Fotos einer schwarzen Katze. Bei einem Foto kann nicht mehr streng zwischen referentieller Bezugnahme auf ein Subjekt und einer Prädikation unterschieden werden. Während angesichts einer realen Katze über diese eine Aussage bzw. Prädikation gemacht werden kann, greifen bei einer Repräsentation Referenz und Prädikation ineinander und werden ununterscheidbar. Analog verhält es sich, wie Ankersmit (ebd.: 15) zeigt, mit historiographischen Darstellungen: Eine neue Studie über die Renaissance ist nicht etwa eine neue Aussage über ein klar abgegrenztes Thema bzw. Subjekt, sie hat vielmehr das Potenzial, den Gegenstand selbst in der Vorstellung der Rezipienten signifikant zu verändern. In geschichtswissenschaftlichen Darstellungen über die Epoche der Renaissance können Aussagen de dicto nicht klar von Aussagen de re unterschieden werden, ${ }^{6}$ nicht minder gilt dies für die Repräsentation von Geschichte, die in historischen Dramen erfolgt. Angesichts einer Studie über ein be-

${ }^{6}$ Mit der Problematisierung der dichotomischen Unterscheidung von de-dicto und de-reWahrheiten (also zwischen analytischen und empirischen Aussagen) hat Willard von Orman Quine den sogenannten linguistic turn in der Philosophie markiert. Die Bedingungen für eine Aussage de re sieht Quine entsprechend im ,epistemischen Kontakt“" mit dem besprochenen Sachverhalt, während Aussagen, denen kein solcher Kontakt vorausgeht, die also allein medial vermittelt sind, de dicto-Charakter zukommt. 
stimmtes Thema der Geschichtswissenschaft ist man vielleicht eher geneigt, zu meinen, der Historiker beziehe sich auf klar abgegrenzte reale Ereignisse, insofern man nämlich der Meinung ist, es handelt sich um mehr oder weniger korrekte de re-Aussagen über diese. Angesichts eines Dramas oder eines Spielfilms über den Spartakus-Aufstand etwa aber wird man sagen, das Drama bzw. der Film handle von diesem Ereignis; man beginge einen ontologischen Fehler, diese Repräsentation für eine wahre oder falsche Aussage über die Realität zu halten, und sei die Machart auch noch so „realistisch“. Mit Texten der Geschichtswissenschaft verhält es sich so zumindest Ankersmit - ähnlich: Entgegen der weitverbreiteten Ansicht, die Historiographie treffe wahre oder falsche Tatsachenaussagen, postuliert er, dass Texte der Historiographie mehr oder weniger Ähnlichkeit mit der historischen Realität haben, von der sie handeln.

Insofern die Historiographie wie auch die Literatur Repräsentationen der außersprachlichen Realität liefern, sind sie - was ihren Realitätsbezug betrifft - nur graduell voneinander verschieden. Abgesehen von der skizzierten Genealogie historischer Belletristik (ihrer Verschränktheit mit der Geschichtsschreibung), gibt es also auch sprachtheoretische Gemeinsamkeiten zwischen diesen beiden Arten, Geschichte darzustellen, womit der Umstand besser verständlich wird, warum es überhaupt diachrone Veränderungen in den repräsentierenden Genres Geschichtsschreibung bzw. historisches Drama geben kann. Denn hätte man es mit „einfachen“ referentiellen Bezügen und Prädikationen zu tun, ließen sich leichter wahre von falschen Aussagen über geschichtliche Ereignisse unterscheiden, und es gäbe weniger Vielstimmigkeit und stattdessen eher Eindeutigkeit in Texten mit geschichtlicher Thematik. So aber liefern die Repräsentationen unterschiedliche Bilder von Gegenstandsbereichen; die diversen Texte referieren also keineswegs ,starr“ auf die historische Welt.

In literaturwissenschaftlichen Arbeiten zu historischer Belletristik - gleichgültig, ob es sich um Drama, Lyrik oder Epik handelt - wird sehr oft auf das Verhältnis dieser Texte zu ihren historiographischen Prätexten bzw. Quellen abgehoben, um die spezifischen Unterschiede des literarischen Textes - den „Mehrwert“, welchen dieser gegenüber seinen Vorlagen darstellt - zu diskriminieren. Eine solche vergleichende Analyse liefert tatsächlich meist gute Einsichten in das „Pathos“ des belletristischen Textes, dessen Darstellung eines historischen Ereignisses in entscheidenden Punkten von den geschichtswissenschaftlichen Prätexten abweichen und damit eine andere Erklärung und eine andere ideologische Position implizieren kann. ${ }^{7}$

Zugleich jedoch schränkt eine solche Untersuchung die Analysemöglichkeiten deswegen ein, weil die Berücksichtigung intertextueller Bezüge und Differenzen zwar bei einigen wenigen Texten durchführbar ist, mit dem Anwachsen der Zahl li-

${ }^{7}$ So ist etwa Karamzins Istorija Gosudarstva Rossijskogo, die wichtigste Vorlage für Boris Godunov, in ihrer Charakterzeichnung weniger differenziert und komplex als die puškinschen Figuren (vgl. Lotman 1996: 188). 
terarischer Primärtexte aber zu umfangreich und komplex wird, gilt es doch mögliche Prätexte von verschiedenen „manifesten“ literarischen Texten zu betrachten, um zu Schlüssen über den Primärtext zu kommen. Abgesehen von der Schwierigkeit, eine größere Anzahl literarischer und geschichtswissenschaftlicher Texte synoptisch $\mathrm{zu}$ vergleichen, ist vor allem die qualitative Besonderheit literarischer gegenüber historiographischer Repräsentation zu beachten. Beide ,handeln von“ etwas, beide „stellen“ etwas „dar“ (darin besteht laut Ankersmit ihre Gemeinsamkeit); während aber die Geschichtsschreibung die realen Ereignisse mit den Strata Chronik, Fabel, Erklärung überformt und dabei den Eindruck vermittelt, eine Beschreibung von realen Ereignissen zu liefern, produziert namentlich das historische Drama Ereignisse zweiter Ordnung in einem virtuellen Raum, wobei dem dramatischen Text zumindest die „whiteschen“ Strata Fabel und Erklärung für die vorgeführten Ereignisse zu fehlen scheinen. Für das historische Drama als Repräsentation gilt dennoch dasselbe wie für alle anderen Repräsentationen: Es gehorcht bestimmten Gesetzen - der Kohärenz, Extension und Konsistenz - welche für die historische, textuell nicht repräsentierte Wirklichkeit selbstverständlich nicht gelten (vgl. Ankersmit 2002: 22 f.). Dementsprechend können mit diesen Ereignissen zweiter Ordnung, die vom dramatischen Text repräsentiert werden, die Strata Chronik, Fabel und Erklärung auf eine ähnliche Weise verbunden werden, wie dies in der Geschichtsschreibung funktioniert. Repräsentiert ein historisches Drama also geschichtliche Ereignisse, sind in den Text - gleichsam eine Partitur der szenischen Ereignisse - „Fabel“ und „Erklärung“ als Strata historiographischer Repräsentationen „eingefaltet“, sie können bei der Analyse des dramatischen Textes dementsprechend wieder ,ausgefaltet" werden, ohne dass dafür auf die historiographischen Prätexte historischer Dramen zurückgegriffen werden müsste. Das historische Drama ist demnach als Text sui generis zu betrachten, der Ereignisse zweiter Ordnung - szenische Ereignisse - als Repräsentation produziert und - anders als bei realen historischen Ereignissen erster Ordnung - die historiographischen Strata Fabel und Erklärung eingefaltet enthält. Man betrachte die hypothetische Kette:

Ereignisse erster Ordnung [= reale Ereignisse bzw. res gestae] $\rightarrow$ Chronik $_{1} \rightarrow$ Fabel $_{1} \rightarrow$ historiographische Erklärung ${ }_{1} \rightarrow$ (historisches Drama qua Partitur $\rightarrow$ Ereignisse zweiter Ordnung [= repräsentierte Ereignisse] $) \rightarrow$ Chronik $_{2} \rightarrow$ Fabel $_{2} \rightarrow$ historiographische Erklärung $_{2} \ldots$

Sie macht ersichtlich, dass die (historiographischen) Erklärungen auf Ereignisse - reale oder repräsentierte - ,folgen“ und dass es unterschiedliche Betrachtungsweisen dieser Kette gibt. Während (zumindest ihrem orthodoxen Selbstverständnis nach) Historiker primär ,,reale Ereignisse“ mit Darstellungen und Erklärungen bedenken, thematisieren Kultur- oder Literaturwissenschaften unterschiedliche Aspekte der Kette, sie beschäftigen sich aber weniger mit einer Erklärung der Ereignisse 
erster Ordnung. ${ }^{8}$ Ihr Verfahren kann darin bestehen, die Repräsentationen zweiter Ordnung mit historiographischen Repräsentationen zu vergleichen (was wie gesagt ein oft gewählter Ansatz bei der Analyse von historischen Dramen ist), es kann als Whitesche „Metahistory“ bevorzugt die Historiographie analysieren, oder die literarischen Repräsentationen von Geschichte kulturwissenschaftlich gesondert fokussieren. Letzteres ist wie gesagt der hier vertretene Ansatz, mit welchem die Veränderungen des historischen Dramas in einem Zeitraum von ca. 50 Jahren untersucht werden sollen. Die Konzentration auf die dramatischen Texte und die an diese anschließbaren Strata zweiter Ordnung impliziert eine Abstandnahme von sowohl den realen Ereignissen selbst wie auch von den an diese angeschlossenen Strata erster Ordnung, sie trägt aber dem Umstand Rechnung, dass diese literarischen Repräsentationen von Geschichte eigenen gattungsspezifischen Regeln folgen, die weder in den repräsentierten Ereignissen selbst noch in den historiographischen Prätexten ihren Grund haben.

Die doppelt hybride Struktur des historischen Dramas (neben der bereits von Nünning festgestellten Mischung von Facta und Ficta ist es eine Partitur von Ereignissen wie auch Repräsentation von solchen) gestattet es, aus ihm die Fabel zu extrapolieren, um in dieser die eingefalteten „Erklärungen“ auszumachen, welche den Ablauf der Ereignisse verständlich machen sollen. Unter „Erklärungen“ subsumiert White verschiedene Modi, die mehr oder weniger explizit die Verbindungen von Ereignissen herstellen. Im Fall des historischen Dramas, wo sowohl eine ausformulierte Fabel wie auch eine entsprechende Erklärung an der Textoberfläche fehlen, latent bzw. eingefaltet aber vorhanden sind, liefert die „Fabel“ selbst die zentrale Grundlage für die Erklärung. Die gattungsspezifische Kohärenz des Dramas - die Einheit der „Handlung“, welche als die wichtigere im Vergleich zu den meist freier ausgeführten Einheiten Zeit und Ort gelten kann (vgl. Asmuth 1994: 192 f.) - lässt nämlich Handlungsketten und Zusammenhänge deutlich werden, während andere explizite Erklärungsmuster in den Hintergrund treten. ${ }^{9}$ In die vom dramatischen Text dargestellten Handlungsketten fließen verschiedenartige Faktoren ein, die bei der Analyse des Textes zu berücksichtigen sind, wenn dem kulturellen bzw. ideologischen Gehalt von Dramen und der gattungsspezifischen szenischen Repräsentation geschichtlicher Vorgänge nachgespürt werden soll.

${ }^{8}$ Das Anliegen von Ankersmit besteht darin, historiographische Texte nicht als wahre oder falsche Aussagen über Ereignisse, sondern als Repräsentationen begreifen zu lassen (mithin sind sie kategorisch nicht vom historischen Drama verschieden), White hingegen meint, dass Verfahren und Traditionen aus Genres, die Repräsentationen sind, in die Historiographie hineinspielen und von dieser nicht immer reflektiert werden.

9 Im dramatischen Text können auktoriale Erklärungen ja nur indirekt zum Ausdruck kommen oder einzelnen dargestellten Figuren ,,in den Mund“ gelegt sein, was diese zu „Sprachrohren“ des Autors macht. Nicht immer freilich sind solche eindeutig zu bestimmen, überdies gilt es der strukturellen „Gleichwertigkeit“ der Figurenreden Rechnung zu tragen. 
Angesichts der Anzahl der im Laufe von knapp einem halben Jahrhundert entstandenen historischen Dramen - wie in der ersten Fußnote angesprochen, verstehe ich die Gattung in einer „weichen“ Definition, womit klare gattungstypologische Abgrenzungen hinfällig werden - ist es vonnöten, vom jeweiligen historischen Gehalt der exemplarisch ausgewählten Texte möglichst zu abstrahieren, da auf der Ebene der repräsentierten Ereignisse die historischen Dramen wenig Gemeinsamkeiten haben. ${ }^{10}$ Anders gesagt, sie handeln von unterschiedlichen Stoffen und sind auf dieser Ebene inkommensurabel - eine Untersuchung dessen, welche Veränderungen das historische Drama zwischen 1880 und 1930 erfahren hat, muss vielmehr auf das Stratum der „Erklärungen“ abzielen, das in den Dramen eingefaltet ist und das an die Fabel des Drama anschließt. Diese „Erklärungen“ ergeben sich in der Betrachtung der verschiedenen Faktoren, die den Verlauf der repräsentierten Ereignisse bestimmen und die in der Fabel am besten ausgemacht werden können.

III. Jaroslav Vrchlickýs „tschechische Trilogie“ (Česká trilogie: Drahomíra (1882), Bratři (1889), Knižata (1903)) zeichnet die Probleme politischer Herrschaft vor dem Hintergrund des frühen Přemyslidenreiches, das sich gegenüber den expansiven deutschen Nachbarn behaupten muss. Laut Berwanger (2003: 58) diente der Rückgriff auf die Zeit der Přemysliden als Gründungserzählung zur Festigung der nationalen Einheit der Tschechen, deren markantestes kulturelles Symbol die Eröffnung des Královské Zemské bzw. Národní Divadlo 1881 war. ${ }^{11}$ Die Titelheldin hält am traditionellen Heidentum fest, womit sie in Opposition zu den christianisierten Fürsten gerät, die gegenüber den christlichen Deutschen wenig Widerstand leisten und allzu sehr auf Nächstenliebe vertrauen. Nach dem Tod des Fürsten überträgt der Sněm, die Versammlung des böhmischen Adels, die Herrscherwürde der Witwe Drahomíra in Vertretung für ihren noch minderjährigen Sohn und Thronfolger Václav. Diesem sowie dem zweiten Sohn Boleslav soll allerdings eine christliche Erziehung zuteil werden. Zumal Drahomíra diesen Beschluss des Sněms nicht akzeptiert und ihre Kinder zu sich holt, setzt die Adelsversammlung ihren Beschluss mit Waffengewalt durch und holt die Kinder zurück. Als Fürstin ist Drahomíra eine resolute Gegnerin der Deutschen, sie setzt sich zudem über den Sněm hinweg, der unter ihrer Herrschaft seinen politischen Einfluss verloren hat. Nachdem Drahomíra ihre vom

${ }^{10}$ Die Nachrangigkeit des gewählten Stoffes und die Vorrangigkeit der „Erklärungen“ in Repräsentationen macht auch den befremdlichen Umstand verständlich, dass ein und derselbe Autor (J. K. Tyl) in demselben Jahr 1848 sowohl ein Stück über Jan Nepomuk (Johannes Nepomuk), den Heiligen der Gegenreformation, wie auch über Jan Hus schreiben konnte, und beide gleichermaßen als Titelhelden einer patriotisch ausgerichteten Tragödie fungierten (vgl. Mazáčová 1997: 8).

11 Zumal das Theater bald nach der Eröffnung abbrannte und zwei Jahre später wieder eröffnet wurde, gab man anspruchsvolle tschechische Theaterstücke weiterhin auf dem Prozatimní Divadlo, der so genannten Interimsbühne, zur Aufführung; auf dieser hatte auch Drahomíra 1882 Premiere. 
christlichen Geist erfüllte Schwiegermutter Ludmila, die Erzieherin von Václav und Boleslav, ermordet, erwartet sie sich die Rückkehr ihrer Kinder. Diese, bereits christlich denkend, sind aber ob dieser Bluttat entsetzt und verweigern die Rückkehr zur Mutter. Der Sněm, der sich als Quelle des Rechts versteht, beschließt umgehend die Machtübertragung auf den noch jungen Václav, er tut dies aber aus eigenem Interesse. Demgegenüber stellt Drahomíra die Gesamtheit des Reiches, die über den partikularen Interessen der im Sněm vertretenen Adeligen stehe und die allein sie selbst zu verteidigen meint. ${ }^{12}$

In Bratři (1889, UA 22. 04. 1889 im Národní Divadlo) sieht Drahomíra die Folgen der Wahl Václavs durch den Sněm. Václav nämlich ist in seinem Herrschen ganz vom christlichen Geist geleitet, dabei ignoriert er die machtpolitischen Interessen der Deutschen, mit denen er allzu willfährige Friedensverträge abschließt (Radslav, der Sprecher des Sněm, ist daher zu einem erklärten Gegner Václavs geworden). Wenngleich Václav mit seiner christlichen Nächstenliebe politisch wenig Erfolg hat, ist ihm ein besonderes Charisma eigen, welches auf nahezu übernatürliche Weise den Widerstand seiner Gegner bricht. Nur durch Mord kann Boleslav seinen Bruder überwältigen und selbst die Herrschaft über Böhmen antreten. Boleslav ist politisch erfolgreicher als Václav, ihm gelingt es, größere Zufriedenheit bei der Bevölkerung zu erringen. Wegen des Mordes plagen ihn und seine Mutter aber schwere Schuldgefühle. In Bratři ist deutlich ein Antagonismus zwischen irdischer und himmlischer Herrschaft zu erkennen, der allerdings nicht vorschnell einseitig betrachtet werden darf. Denn Václavs Heiligkeit verleiht diesem zwar großes Charisma sowie langen Nachruhm, es ist dabei aber nicht zu übersehen, dass diese christliche Auffassung von Herrschaft sehr weltabgewandt ist; ihre politischen Erfolge - etwa der Friede mit den Deutschen - erscheinen zweifelhaft. ${ }^{13}$ Der Antagonismus zwischen himmlischer und irdischer Herrschaft wird ferner dadurch akzentuiert, dass Václav wegen der Schwierigkeit, im Gefüge der Welt seine christlichen Grundsätze zu verwirklichen, sogar zugunsten von Boleslav auf seine Fürstenrolle verzichten wollte, dazu konnte es tragischerweise wegen des vorschnellen Mordes durch Boleslav nicht kommen: Wirksame politische Herrschaft auf Erden erscheint mithin als gewalttätig und schuldbehaftet, die himmlische Herrschaft als nicht in dieser Welt realisierbar. ${ }^{14}$

12 Während in einer Version der fünfaktigen Tragödie aus dem Jahre 1882 Drahomíra aus Enttäuschung über die Abkehr der Kinder Selbstmord begeht, lebt sie in der ursprünglichen handschriftlichen Version weiter. Letztere eignet sich somit besser für die Aufführung der gesamten Trilogie, die auch vom Národní Divadlo geplant war, wenngleich die Dramen der Trilogie immer nur einzeln aufgeführt wurden.

13 Vrchlický überspitzt hier das bereits in J. K. Tyls Krvavé křtiny čili Drahomíra a jeji synové angelegte zwiespältige Václav-Bild (vgl. Cerný 1969: 339).

14 Interessant an Bratři ist auch der Umstand, dass die vor allem im obrození immer wieder vorgebrachte slawische Einheit, die natürliche Verwandtschaft der Slawen (vgl. Vlček 2006), von allen Figuren skeptisch betrachtet wird. So meint etwa Václav, dass es keinen starken slawischen Stamm gebe, bloß Ruten, die an fremden Ufern wachsen und vom Meer erfasst zu werden drohen: „Žel bohu není Slovanstvo ten kmen, / jest proutí jenom, 
Knížata (1903, UA Národní Divadlo 29. 10. 1903), der dritte Teil der Tschechischen Trilogie, spielt zwei Generationen nach dem in den ersten beiden Teilen dargestellten prominentesten tschechischen Fürsten Václav ${ }^{15}$ : Im Stück werden unterschiedliche Herrschercharaktere vorgeführt, die alle den Namen Boleslav tragen und jeweils verschiedene Konzeptionen verfolgen: Der polnische Herrscher Boleslav Chrabrý (= Bolesław I. Chrobry) wird von einem zu den Polen geflüchteten tschechischen Adeligen als vorbildlicher Fürst dargestellt, der sich um sein Volk kümmert und große politische Pläne (von einem starken Slawentum und von der Abwehr gegen die Deutschen) hat. Boleslav Chrabrý betrachtet die tschechische Situation von ,außen“ und kommt zur Überzeugung, dass in Böhmen niemand in der Lage ist, das Land zu führen. Dementsprechend groß ist sein Appetit auf Böhmen, dessen innenpolitische Schwierigkeiten ihm nur zupass kommen, um es in seinen Einflussbereich bringen zu können.

Die tschechischen Boleslavs umfassen drei Generationen: Die Politik von Boleslav I. gegenüber den Deutschen wird im Stück von den Nachkommen positiv dargestellt, dessen Mord an Václav erweist sich aber als verhängnisvoll, von der Schuld seines Vaters entsetzt, verhält sich sein Sohn Boleslav Pobožný deutschfreundlich, der andere Sohn Křištan (Strachkvas) wird als wahnsinnig aufgrund des Brudermordes dargestellt. Boleslav III (Ryšavý) wiederum ist nach seinem Großvater geraten: Er ist allein um die eigene Macht besorgt, der Versuch, mit dem verfeindeten Geschlecht der Vršovici eine dauerhafte Aussöhnung zu erreichen, scheitert unter anderem auch aus dem Grund, dass Boleslav autokratisch herrscht und niemals den Sněm einberuft. Innere Rivalitäten einerseits, Machtgier einzelner andererseits führen also in Knižata zur Fremdherrschaft; neben diesem resignativen Schluss zeigt das Drama auch die Auswirkungen vergangener Taten auf nachfolgende Generationen. Die Last schwerer Schuld kann nicht abgeschüttelt werden: Zwei Versuche, historische Schuld willentlich aufzuheben (die Heirat zwischen den Kindern der verfeindeten Familien der Vršovici und der Přemyslovci, Boleslav Ryšavýs Schwur, auf persönliche Rache zu verzichten), scheitern, weil letzlich tiefliegende Hassgefühle zwischen den Familien das Handeln leiten.

Die Tendenz von Vrchlickýs Schlussstück der Trilogie geht folglich dahin, dass Fremdherrschaft über Böhmen insofern unvermeidlich ist, als die tschechischen Führungskräfte in Streitigkeiten befangen sind und das Land nicht regieren können.

jež se ohýbá / dle silných větrů boư̌ných nárazů. Však třeba počítati s tím, co jest. Kmen musí z kořene růst $\mathrm{v}$ celistvosti, / být jednou bytostí, jej z různých větví / a proutků nespojíš, a to náš trest / a kletba naše, rozsazeni jsme jak proutí podél břehu cizoty: Ta pere $\mathrm{v}$ nás, zde třeba obstáti, ne odporem, spíš moudrou rozvahou a dobrou vưlí ukonejšit moře, než pro vždy roztrhá nás ze všech stran. Snad časem take vrostem v pevnou obec, / bůh proto přec nás nepostavil v svět, / by zas nás bez účelu nechal smésti / v plen cizotě. Jen víru v sebe mějme / a klid a moudrost', ostatní dá čas.“ (Bratři I/9, 137)

15 Eine anschauliche Darstellung der wechselhaften Konjunktur der Václav-Verehrung gibt Rak 1994: $37 \mathrm{ff}$. 
Drahomíra und Bratři zeigen einen Widerspruch von Interessen, die unterschiedliche Prioritäten haben: Die weiblichen Rivalinnen in Drahomíra streiten zwar um die Kinder Václav und Boleslav, ihr Antagonismus besteht aber darin, dass Ludmila die Verbreitung des Christentums über alles setzt (und ihr deswegen der deutsche Einfluss auf Böhmen recht ist), während ihre Mörderin vor allem ein starkes und autonomes Böhmen favorisiert und daher auch gegen eine christliche Allianz mit den Deutschen ist. Noch weniger vermittelbar erscheint der Antagonismus im zweiten Teil, der die Alternative zwischen einem starken Böhmen unter Boleslav oder der weltabgewandten transzendenten Heiligkeit Václavs zeichnet. ${ }^{16}$ Von den beiden ersten Teilen der Trilogie unterscheidet sich Knižata vor allem dadurch, dass die Frage, wie Christentum und erfolgreiche Politik vereinbart werden können, in den Hintergrund tritt; der Wille zur Macht erscheint als einzige Motivation für politisches Handeln. Insofern dieser Wille egomanisch ist und die Alleinherrschaft anstrebt - Boleslav Ryšavý möchte seine Brüder töten und er missachtet den Sněm, auch die anderen Parteien verfolgen allein ihre Interessen - gerät Böhmen in eine veritable Krise, in der auch die wenigen positiven Ansätze - wie die Heirat zwischen den verfeindeten Familien - misslingen. Anstelle falscher bzw. vorgeschobener Gründe und bloßer Machtgier wäre Versöhnung notwendig, diese Chance wird freilich nur als nicht realisierte Möglichkeit dargestellt. ${ }^{17}$

Der aus einer deutsch-jüdischen Unternehmerfamilie stammende, sich jedoch für das Tschechentum einsetzende Dichter Julius Zeyer schrieb 1893 mit Neklan (UA 30. 03. 1896, Národní Divadlo) eine an klassische Muster angelehnte Tragödie. Der aus der Chronik des Hájek z Libočan stammende Stoff aus der vorhistorischen Zeit der Stammesherzogtümer handelt vom Konflikt um die Vorrangstellung unter verschiedenen Teilfürsten. Die Titelfigur ist als Herrscherpersönlichkeit schwach: Der Prager Fürst Neklan fürchtet jede Auseinandersetzung und muss sich in vielen Dingen auf seine Berater und Mitstreiter stützen, welche eigentlich die Geschicke des Prager Fürstentums lenken. In Vlastislav, dem Fürsten der Lučanen, hat Neklan

${ }^{16}$ In den Déjiny českého divadla, dem in der „Normalisierung“ entstandenen großen Referenzwerk der tschechischen Theatergeschichte, wird die Apotheose am Ende von Bratř $i$ (der politisch erfolgreiche Boleslav bereut heftig und verspricht, Václavs christliche Vision entsprechend zu verbreiten) pflichtgemäß als verlogener Kompromiss dargestellt (vgl. Klosová 1977: 106). Aus der hier vorgeschlagenen Sicht erscheint dieses Urteil zumindest insofern als richtig, als Vrchlickýs Ausgestaltung des brüderlichen Konflikts nahe legt, dass erfolgreiche Politik auf Erden nicht auf christlichen Grundsätzen beruhen kann.

17 Eine womöglich allzu raffinierte Interpretation des Maskenmotivs in Knižata - hehre Anliegen als Begründung für politische Unternehmungen werden von einer Figur als skraboška (Maske) abgetan - gibt Berwanger (2003: 72 ff.). Sie sieht nämlich auch die Idee der Versöhnung (zwischen den verfeindeten tschechischen Familien) als Maske; Vrchlický würde in Knizzata das Versöhnungspathos verwerfen, das im nationalen Geschichtsdrama - und dessen Performanz im Národní Divadlo - angelegt ist. Eher scheint Vrchlický in diesem Stück, dem sowohl übersinnliche Momente wie auch herkömmliche dramaturgische Kunstgriffe weitgehend fehlen, ein finsteres „realistisches“ Bild der Geschichte zu zeichnen, dessen positive Momente nur angedeutet sind. 
einen ehrgeizigen und kampflustigen Rivalen um die Vorrangstellung. Entschieden wird die Auseinandersetzung durch den bereits christlich denkenden Ritter Tyr, der seine Kampfstärke für das bestehende Recht investiert, wonach er Neklan als Prager Fürsten die Vorrangstellung zugesteht. Aufgrund eines Missverständnisses ${ }^{18}$ wird diese ideale Herrscherfigur getötet, so dass zum blutigen Ende der Tragödie die Hoffnung auf eine bessere Zukunft im Sohn Neklans weiterlebt, der allein die jugendliche Kraft der Versöhnung verkörpert. Die Fabel legt eine Verurteilung von rechtswidriger Machtgier nahe; die legitimistische Position wird aber gleichfalls durch die reale Schwäche Neklans sowie durch die Stärke des dynastisch nicht legitimierten Tyr relativiert, der gegenüber historischen Ansprüchen äußert: „Nač rozjímat o krvi otců svých, / a zdroj svých skutků hledat pouze v ní? Být otcem velkých činů lépe jest, / než pouze synem velkých otců být.“ (Zeyer 1896: 80) Die Abkehr von der Vergangenheit erfolgt weiters durch die Apotheose jugendlicher Unschuld am Schluss, welche alte Feindschaften vergessen können wird.

1903, im Jahr, in dem Vrchlickýs Knižata seine Uraufführung erlebte, schrieb Alois Jirásek sein historisches Drama Jan Žižka (UA 04.07.1903, Národní Divadlo), in welchem der militärische Führer der Hussiten zum glücklichen Ende davon abgehalten werden kann, gegen Prag zu ziehen. In Vrchlickýs Knižata gibt es keine wirklich positive Hauptfigur, Jiráseks Žižka gibt hingegen eine weitgehend positive Gestalt ab, deren subjektive Beurteilung der Situation fast immer mit der objektiven Entwicklung der Ereignisse zusammenfällt. Auch noch seine Absicht, Prag zu zerstören, wird als gerechtfertigt dargestellt, dass er schließlich davon ablässt, hat seinen Grund in der Reue der Prager und in Žižkas Großmut. Mit einem Angriff auf Prag hätte Žižka die Stadt dafür bestrafen wollen, dass sie während seiner Abwesenheit, während er gegen die ,äußeren Feinde“ der Hussiten kämpft, mit katholischen Adeligen paktiert. Wenngleich das historische Setting von Jiráseks Drama also ein ganz anderes ist als dasjenige von Vrchlickýs Knižata, kann in beiden Stücken der auktoriale Appell an die nationale Einigkeit ausgemacht werden. Die Feinde der positiven Figuren in Jiráseks Stück sind alle Gegner der Utraquismus, allerdings können auch allzu radikale Kräfte im hussitischen Lager insofern als problematisch gelten, als sie gemäßigtere hussitische Adelige abstoßen und somit zu einem fatalen Pakt mit dem katholischen Gegner bringen. Das von Žižka verteidigte Hussitentum erscheint bei Jirásek insofern als Kern der tschechischen Nation, als alle Gegner als Feinde des Hussitentums zugleich auch als Feinde der tschechischen Sprache bezeichnet werden. Gegenüber diesen gilt es, sich der Notwendigkeit einer nationalen Einigung bewusst zu werden und von Extremen - sei es in Richtung des fundamen-

18 Die Tragik seines Todes besteht darin, dass er von einem transzendenten Reich sprach, aber vom heidnischen Berater Neklans missverstanden wurde, der meinte, Tyr hätte irdische Machtansprüche und wäre somit ebenfalls ein gefährlicher Konkurrent Neklans. (Tyrs Vision von einem christlichen Reich anstelle der heidnischen Welt mutet ähnlich weltabgewandt an wie das Christentum Václavs in Vrchlickýs Bratři.) 
tal klassenkämpferischen Hussitismus, sei es in Zugeständnissen an den Katholizismus - abzusehen.

In Falkenštejn von Jaroslav Hilbert, dem dritten 1903 entstandenen historischen Drama bildet - wenig überraschend - erneut der Konflikt zwischen der nationalen Eigenstaatlichkeit Böhmens und der Subordination unter den deutschen Einflussbereich den Hintergrund. Nach dem Tod von Otokar Přemysl II. ist es mit der böhmischen Selbstständigkeit dahin: Der noch minderjährige Thronfolger Václav ist mit Hilfe von Záviš aus deutscher Gefangenschaft zurückgekommen, die Königswitwe Kunhuta steht im Zwiespalt zwischen Záviš von Falkenštejn und den dynastischen Banden der Přemysliden. Die Ambitionen von Záviš, der sich auf die Familie der Vítkovici stützt, sind eine wichtige Hilfe bei der Stärkung des Landes, Záviš jedoch will die Liebe Kunhutas dafür nützen, selbst König zu werden und die Přemyslidendynastie abzulösen. Der dynastisch nicht legitimierte Záviš gilt im Stück als die einzige politische Kraft, die Böhmen dauerhaft souverän halten will, während der Bischof Dobeš mit abgefeimten Mitteln die Habsburgerherrschaft über Böhmen anstrebt. Wenngleich Hilbert alle Parteigänger für fremden Einfluss auf Böhmen als gänzlich unsympathisch zeichnet und damit ein kontrastreiches Bild der nationalen Antagonismen zwischen Tschechen und Deutschen/Österreichern schafft, besteht die Originalität seines Werkes darin, dass er in Záviš und Kunhuta ein Paar zeigt, dessen Bindung aneinander tragisch ist: Kunhuta weiß um die einzigartigen politischen Qualitäten von Závišs, der es auch vermag, ihr Václav zurückzubringen, als sie aber erkennen muss, dass Záviš über die Verbindung mit ihr die böhmische Königsmacht anstrebt und den schwachen und naiven Thronfolger Václav ausschalten würde (wie er auch vor blutiger Gewalt nicht zurückschreckt, wenn er auf Widerstand trifft), verstößt sie den Geliebten erbittert und verbündet sich mit dessen Gegnern, die ihrerseits aber gleichfalls über Václav bestimmen und ihn klein halten. Zumal diese Gegner nur eigene, tschechenfeindliche politische Ziele verfolgen, sieht Kunhuta keinen anderen Ausweg als den Tod. Indem sie Záviš verstieß, wollte sie ihren Sohn retten, doch wäre nur Záviš in der Lage gewesen, den Sohn und mit ihm Böhmen zu retten. Auch Záviš nimmt den Tod auf sich, weil er keinerlei Zugeständnisse an die habsburgerfreundliche Politik seiner Gegner machen möchte.

Vergleicht man die drei 1903 uraufgeführten Geschichtsdramen von Jirásek, Vrchlický und Hilbert, offenbaren sich die ideologischen Unterschiede wie auch die Gemeinsamkeiten. Letztere bestehen im Verhältnis der Tschechen zu ihren Nachbarn. Namentlich Deutsche und Ungarn erscheinen in der historischen Belletristik ausnahmslos als Feinde (vgl. Borová 1995: 38). Dieses Verhältnis zu den Nachbarvölkern stellt allerdings meist den Hintergrund des dramatischen Konflikts dar, zwischen den Hauptfiguren entwickelt sich die Auseinandersetzung innerhalb der Rahmenbedingungen dieses Verhältnisses. In den beiden Vrchlický-Dramen der 1880er Jahre erwächst in diesem Rahmen die Aporie von christlicher Nächstenliebe und nationaler Selbstbehauptung, im Drama von 1903 wird innerhalb des Rahmens die Konsequenz egoistischen Machtstrebens vorgeführt: Schierer Wille zur Macht 
schlägt dahin um, dass die Nachbarvölker über die Tschechen dominieren. Eine ähnliche Erklärung für die Ereignisse ist in Jiráseks Jan Žižka auszumachen, wenngleich die Handlung vierhundert Jahre später spielt. Auch Zeyers Neklan kulminiert im dramatischen Appell an nationale Eintracht, in Hilberts Falkenštejn führt der Konflikt um die Macht zwischen den tschechischen Parteien zum Untergang derjenigen, die gegen eine Unterordnung unter eine Fremdherrschaft sind. Erfolgreiches politisches Handeln impliziert hier auch die Anwendung moralisch fragwürdiger Mittel. Anders als Jiráseks Jan Žižka, der als beinahe perfekter Nationalheld gezeichnet ist, leitet die Handelnden in Knižata und Falkenštejn der Wille zur Macht: Vrchlický sieht darin - wie schon Bratři gezeigt hat - das Dilemma des Politischen, Hilbert hingegen stellt in Záviš eine Figur dar, deren machiavellische Unternehmungen effizient erscheinen.

IV. Im Unterschied zur tschechischen historischen Belletristik, die im 19. Jahrhundert die Spannungen zwischen den Tschechen und ihren geographischen Nachbarn thematisierte, kreiste die russische historische Dramaturgie des 19. Jahrhunderts vorwiegend um zwei politische Probleme: um die Autokratie einerseits, um die Frage des Samozvanstvo andererseits. Die politischen Implikationen der Selbstherrschaft fanden in der Dramaturgie insofern Entsprechung, als die Handlung in den entsprechenden Stücken, die meist in der Zeit Ivans IV. angesetzt sind, von der Figur des Autokraten vorangetrieben wird. Die Figur des Usurpators hingegen bildet solange das Handlungszentrum, solange das Volk an die Rechtmäßigkeit von dessen Ansprüchen glaubt, verliert es diese, verschwindet auch die handlungstreibende Funktion des Prätendenten (vgl. Virolajnen 1987: 332). In den 1860er und 1870er Jahren gingen Autoren wie Dmitrij V. Averkiev und Nikolaj A. Čaev vom Schema der um eine zentrale Handlungsfigur kreisenden Tragödie ab, um mit „Szenen aus dem Volk" geschichtliche Prozesse in gesellschaftlicher Breite zu erfassen (Die offene Szenenfolge von Puškins Boris Godunov bildet hierfür meist das Vorbild). Trotz der Episierung und Dispersion der Handlung verliert das klassische fünfaktige Tragödienschema - ebenso wie in der tschechischen Literatur - niemals gänzlich an Bedeutung und wird gerade zur Jahrhundertwende wieder neu aktualisiert. Als Beispiel für eine moderne historische Tragödie kann Dmitrij Merežkovskijs Pavel I (1908) gelten, dieses (möglicherweise aus Gründen der Zensur) als drama dlja čtenija konzipierte Stück führt die Ereignisse um die Ermordung von Pavel I. vor. Pavels Nachfolger Aleksandr wird dabei vom geschickt die Palastrevolution steuernden Palen in eine ausweglose double-bind-Situation gebracht: Entweder stimmt er der Absetzung seines Vaters zu oder er wird selbst als Drahtzieher der Verschwörung denunziert. Die Titelfigur Pavel bildet keineswegs das Handlungszentrum, der als brutaler Despot vorgeführte Monarch ahnt zwar etwas vom geplanten Putsch, er begegnet diesem jedoch mit unangemessenen Vergleichen (er sieht sich als Christus mit Dornenkrone) und lächerlichem Verhalten. Der ob der Mitschuld am Putsch und der dabei eskalierenden Gewalt geschockte Aleksandr ist kaum in der Lage, sich 
dem Volk als neuer Imperator zu präsentieren. Zentrum der Intrige ist Palen, die meisten der anderen am Umsturz beteiligten Offiziere werden als gleichgültiger Haufen abenteuernder Adeliger gezeigt, mit denen kein Staat zu machen ist. Merežkovskijs massive Kritik am autokratischen System besteht nicht allein darin, dass die Monarchen nicht mehr imstande sind, die Funktion eines tragischen Helden zu erfüllen, dessen Handeln folgenreich ist. Vielmehr erscheint tragisch, dass der bloße Wechsel an der Spitze der Autokratie, der von heftigen Emotionen der Beteiligten begleitet wird, keine substanziellen Folgen für das Ganze haben wird.

Als „Familienchronik in Dramenform“ hat der Petersburger Autor, Kunsthistoriker und Shakespeare-Übersetzer Petr P. Gnedič seine beiden Stücke um zwei Generationen der Adelsfamilie Plavutiny-Plavuncovy bezeichnet. Zur Gattung historisches Drama können diese beiden Stücke, die offensichtlich ein theatralisches Pendant zu Lev N. Tolstojs Vojna i mir sein sollen, insofern gerechnet werden, als die fiktiven familiären Ereignisse deutlich mit historischem Hintergrund versehen sind. Cholopy (1907) spielt zu Beginn des 19. Jahrhunderts und endet mit der Inthronisierung von Aleksandr (die Palastrevolution wird vage angedeutet), Dekabrist (1909) spannt einen Bogen von den russischen Truppen in Paris zur Aufhebung der Leibeigenschaft. Die Stücke zeigen die Auswirkungen der spätfeudalistischen Gesellschaftsordnung und der Leibeigenschaft auf die zwischenmenschlichen Verhältnisse, sie zeichnen realistisch-naturalistisch die Mikropolitik der Macht (sexuelle Übergriffe der Adeligen auf Leibeigene, das Schicksal der „Bastarde“) in der russischen Gesellschaft, während üblicherweise in historischen Dramen große „makropolitische“ Handlungen der politischen Elite im Mittelpunkt stehen. ${ }^{19}$ Die beiden Theaterstücke enden immer mit einem ambivalenten Schlussbild: Aus der Sicht der Figuren beginnt eine neue Epoche (Thronfolge Aleksandrs, Abschaffung der Leibeigenschaft), eine relativierende oder skeptische Äußerung einer anderen Figur konterkariert aber sofort dieses Pathos. Mit dieser zweistimmigen Bewertung politischer Ereignisse ex ante ist das Publikum herausgefordert, ex post selbst die eigene Geschichte wertend zu betrachten. Diese Schlüsse, die dazu geeignet sind, auf den Abstand der Rezipienten von der repräsentierten Zeit hinzuweisen, unterscheidet Gnedič von anderen Autoren, deren historische Stoffe auf dauernde Aktualität für den Rezipienten optieren und den historischen Abstand von repräsentierter Zeit und Rezeption nicht hervorheben.

19 In der zur gleichen Zeit wie Gnedičs historische Dramen entstandenen Revoluční trilogie (1907-1909) setzte Viktor Dyk die mit seinem Drama Posel (1907) erfolgreich eingeleitete Neukonzeption des historischen Dramas fort. Ähnlich wie Gnedič zeigt Dyk Geschichte auf einer Mikroebene, in einem fiktiven Milieu, in welchem das Handeln der Figuren weniger von makropolitischen oder ethischen Überlegungen, sondern vielmehr von psychischen und sozialen Dispositionen geleitet ist. Sexualität, soziales Ansehen, klassenbezogene Differenzen und Antagonismen ergeben darin eine Verkettung, die vom Einzelnen nicht willkürlich aufgelöst bzw. gesteuert werden kann. 
Velimirs Chlebnikovs Interesse für die Frühgeschichte der nomadischen Steppenvölker fand auch im kleinen Drama Asparuch (entstanden um 1908, Erstveröffentlichung 1914) Niederschlag: In ihm läuft der Feldherr der Protobulgaren Asparuch zu den hellenischen Feinden über, offenbar deshalb, weil ihn dessen Kulte und Sitten anziehen. Seine eigenen Truppen bestrafen ihn mit dem Tod. Diese kurze Wiedergabe des Inhalts mag zeigen, dass Chlebnikovs Asparuch eher zur hybriden Gattung dramatischer Poeme gehört; die Figuren erzählen in den Repliken skizzenartig die wichtigsten Ereignisse der Fabel. Der dramatische „Konflikt“ ist auf die Opposition von der ,skythischen Wildheit“ der Protobulgaren und der hellenischen Kultur, letztlich auf das symbolistische Begriffspaar dionysisch-apollinisch, das auch durch deutliche Farboppositionen der Ausstattung unterstrichen wird (der schwarze Asparuch - die weißen Hellenen) zurückzuführen. Das aus einer Erzählung von Herodot in die bulgarische Frühzeit transponierte Sujet lässt auf keine wesentliche Veränderung der Opposition schließen: Asparuch, der die Fronten gewechselt hat, wird getötet, eine Vermittlung des kulturellen Antagonismus bleibt gänzlich aus. In seiner interessanten Interpretation stellt Duganov (1990: 206 ff.) Asparuch als „kleine Tragödie“ in der Nachfolge Puškins dar, deren Held sich als titanisches romantisches Subjekt gegen das Schicksal und gegen die Natur stellt (in der ersten Szene tötet Asparuch sein Pferd, weil es nicht den eigenen Schatten überholen kann, am Ende empfängt er für seinen Verrat durch seine eigenen Leute den Tod). Ex post hat Chlebnikov dann selbst im Fürsten Asparuch das Modell für den Untergang der Autokratie gesehen: „Свинцовые стрижи много позднее / В каменный утес Романовых / Летели в отместку разрухи / [...] Ранее они летели в «Аспарухе»““ (Chlebnikov zitiert nach Duganov 1990: 210).

Das kurze Drama Chlebnikovs steht paradigmatisch für eine Tendenz, die sich im russischen historischen Drama der 10er und 20er Jahre ausmachen lässt: Die Handlung wird poetisiert, d. h. konkrete historische Konflikte werden als Motiv, Stoffvorlage gewählt, um ein allgemeines antagonistisches Verhältnis (in Asparuch zwischen Herrscher und Untertan bzw. zwischen „Hellenen“ und „Skythen“) zu konnotieren. Die konkrete historische Referenz wird dabei immer weniger wichtig, was sich in der „unhistorischen“ Übertragung der Herodot-Erzählung in die protobulgarische Vorzeit zeigt oder in pseudohistorischen Stoffen.

Nikolaj Gumilev hat mit Gondla (1916) ein Drama geschrieben, welches im 9. Jahrhundert in Island angesiedelt ist und unhistorische Fürstennamen nennt - Gumilev stützte sich auf russische Ausgaben skandinavischer Sagas (vgl. Babičeva 1991: 253 f. u. 258 f.). Der zeitlich und räumlich vom im Krieg stehenden Russland weit entfernte Schauplatz erlaubt Gumilev eine von konkreten historischen Bezügen scheinbar freie Thematisierung ethischer Werte in der Politik. In einem Gespräch hat Gumilev 1917 geäußert, sein Wechsel zur dramatischen Gattung sei dadurch motiviert, dass die Völker Europas von großen Ereignissen erfasst wären, es sei die „Zeit 
des Dramas“ angebrochen (zit. nach Timenčik 1992: 55). ${ }^{20}$ Der irische König Gondla wurde als geeigneter Bräutigam für die isländische Prinzessin Lera gewählt, damit das kriegerische Island, das von inneren Zwistigkeiten wie auch von äußeren Feinden bedroht wird, mit Irland, das bereits christianisiert wurde, enger verbunden wird. Der bucklige und im Kampf ungeschickte Gondla wird aber von den isländischen Recken (den „Wölfen“) nicht akzeptiert, auch seine Frau lässt sich von einem Kämpfer erobern. Die Vision des von Gondla vertretenen Christentums erträumt Lera nur in der Nacht, in der sie zur frommen Laik wird. Ein weiterer Grund, warum Gondla von den isländischen Wölfen verachtet wird, ist seine Herkunft. Denn in Wahrheit ist Gondla gar nicht der vermeintliche irische Prinz; ohne dass er selbst davon wusste, wurde er nur als solcher ausgegeben. Als jedoch aus Irland die Kunde dringt, dass Gondlas leiblicher Vater nach einem Interregnum zum neuen irischen König gewählt wurde und sterbend Gondla zu seinem Nachfolger erkoren hat, wird Gondla von einigen seiner Gegner als König anerkannt, von anderen aber wiederum nicht. Da Gondla den Widerstand gegenüber der Taufe, die er dem Volk bringen möchte, spürt, wählt er den Freitod, zum einen, um ins transzendente Land der Gnade zu fahren, zum anderen sieht er sich als Opfer, als „Münze“, mit der Gott die Rettung der isländischen Wölfe kauft. Auch Gondlas Frau erträumt sich nun das jenseitige Land der Liebe. Gumilev hat in seinem Titelhelden, wie Sečkarev (1966: IV) herausstreicht, eine Idealisierung des dichtenden Sängers vorgenommen, zugleich aber ist Gondlas christlich-poetische Kraft nur transzendent: In der rauen Welt Islands kann sie sich nicht wirklich durchsetzen, ephemer allenfalls gibt sie eine Ahnung von einer besseren Welt. ${ }^{21}$ In dieser Flucht des christlichen Fürsten aus einer „heillosen“, brutalen Welt erinnert Gondla an Vrchlickýs Václav-Drama Bratři.

Otravlennaja tunika, ein zweites um die Zeit des Revolutionsjahres 1917 entstandenes Drama von Nikolaj Gumilev, spielt im Konstantinopel des 6. Jahrhunderts zur Zeit von Kaiser Justinian. Wiederum sind keine konkreten historischen Bezüge zur russischen Geschichte bzw. zur damaligen Gegenwart zu erkennen, die im französischen Klassizismus formulierten strengen Vorgaben für den Aufbau einer Tragödie (abgesehen von den drei Einheiten und dem beschränkten Figureninventar auch die Auftrittsfolge) sind streng eingehalten. Die tragische Liebesintrige ist weitgehend unhistorischen Charakters, sie wird von Feodora, der zweiten Frau des Kai-

${ }^{20}$ Gumilevs Erklärung korrespondiert mit der bekannten geschichtsphilosophischen Gattungstypologie von Georg Lukács, der das Drama als symptomatisch für die Anzeige gesellschaftlicher Widersprüche ansieht (vgl. Lukács 1965: 116 u. 180 ff.).

21 Die „Fabel“" in Kurzform: Die isländische Lera wird mit dem aus Island stammenden Gondla verheiratet $\rightarrow$ Widerstand im isländischen Adel $\rightarrow$ Lera wird von Lage verführt und ist fürderhin zwischen Heidentum (als „Lera“) und Christentum („Laik") gespalten $\rightarrow$ Gondla kann sich nicht gegen die Erniedrigungen wehren, wähnt sich als Christ dem heidnischen Denken überlegen $\rightarrow$ Gondla ersticht sich, nachdem nicht alle Isländer die Taufe annehmen wollen, er erwartet im Jenseits die Erlösung und hofft mit der Tat die Isländer $\mathrm{zu}$ beeindrucken. 
sers Justinian, eingefädelt; auf tragische Weise fallen ihr Justinians Tochter Zoe, deren Brautwerber, der Car' von Trapezunt sowie Zoes arabischer Geliebter zum Opfer. Sečkarev (vgl. 1966: XXXVI) bemerkt, dass sich die naive junge Prinzessin schuldig am Tod ihrer zwei Verehrer fühlt, wenngleich ihr kein bewusst schuldhaftes Verhalten angelastet werden kann. Diese Konversion von Unschuld zu Schuld erfolgt jedoch unter Bedingungen, die Justinian als billig für seine despotische Herrschaft ansieht: So hält er Fügsamkeit für den unabdingbaren Bestandteil von Macht, damit Übereinstimmung mit dem Willen des Machthabers erreicht wird, die Dispensierung ethischer Regeln begründet er damit, dass auch in der Politik die harten und unverständlichen Gesetze der Natur gälten (vgl. V/3). Zumal schon im ersten Akt Justinians Bemühungen um einen Gesetzeskodex angesprochen werden, bilden diese Auffassung und Justinians unmoralisches Handeln einen scharfen Kontrast. Da sich Justinian als Souverän von der allgemeinen Verbindlichkeit der Gesetze ausnimmt, kommt es zu den tragischen Folgen in seiner unmittelbaren Umgebung und zum Schuldigwerden der Unschuldigen. Justinians Auffassung, dass die kaiserliche Familie ein Muster des staatlichen Lebens abgibt („Мир / В семействе императора прообраз - / Священный государственного мира“" - V/3) wäre demnach im äußeren Kommunikationssystem des Dramas ein politischer Kommentar: In der Familie des Imperators herrscht beileibe kein Friede, ergo gilt dies auch für das Imperium. Wenn der Souverän selbst verbrecherisch handelt, ist davon gleichfalls das von ihm beherrschte Territorium affiziert, unbeschadet sonstiger Bemühungen um die Befriedung desselben. Otravlennaja tunika kann auch als Abgesang auf das russische Imperium verstanden werden, wie dies Babičeva (vgl. 1991: 263) vorschlägt, dabei auf die prinzipiell monarchistische Gesinnung Gumilevs verweisend.

Nach einer Idee von Maksim Gor'kij wurde im Mai 1919 vom Narkompros eine neue, der sozialistischen Gesellschaft adäquate Bildungsoffensive unternommen, die eine ganze Reihe von Szenarien über historische Themen für Bühne und Theater zum Resultat hatte, deren konkrete Umsetzung aber meist nicht erfolgt ist. In der Kommission, die thematische Ideen für diese ,istoričeskie kartiny“ verbreiten, Autoren gewinnen und die eingereichten Texte beurteilen sollte, saßen neben Gor'kij so prominente Autoren wie Aleksandr Blok, Nikolaj Gumilev (das schon 1916 entstandene Gondla wurde von der Kommission jedoch abgelehnt; das Auftragswerk Ochota na nosoroga, ein Stück über die Frühgeschichte der Menschheit, aber angenommen - vgl. Babičeva 1998: 12 ff.), Evgenij Zamjatin, Kornej Čukovskij, die z. T. auch eigene Texte für dieses Projekt verfassten. Das sozialpädagogische Ziel der Unternehmung - man vergleiche dazu Bloks Bemerkungen zu den „historischen Bildern“ (Blok 1962: 422 ff.) - implizierte auch die bereits von Hegel geforderte Nähe des repräsentierten Stoffes zu seinen Rezipienten (vgl. Babičeva 1998: 6 f.). Blok selbst hat dafür „Szenen aus dem Leben des alten Ägypten“ beigesteuert, so lautet der Untertitel seines Stücks Ramzes, das Ende 1919 verfasst wurde und 1921 als letztes Werk zu Lebzeiten des Autors erschienen ist (Blok 1964: 593 f.). Ramzes hat einen überaus detaillierten Nebentext, der zur Beschreibung des altägyptischen All- 
tagslebens und Sozialsystems dient. ${ }^{22}$ Bloks Leistung bestand vorwiegend darin, auf begrenztem Raum einem historisch nicht vorgebildeten Publikum eine Vorstellung vom Leben im alten Ägypten zu vermitteln. Die Szenen spielen in Theben, der Stadtoberste Psaru muss einen Aufstand hungernder Arbeiter verhindern, bevor der Pharao Ramzes II. in die Stadt kommt. Ramzes überhäuft seinen Statthalter für seine Leistungen mit Gold und Geschenken und zieht in den Krieg. Psaru stirbt plötzlich und wird von ganz Theben heftig beweint. Während einerseits das altägyptische Alltagsleben in einer Weise dargestellt wird, die es für das Publikum nur allzu vertraut macht (die Beamten sind bestechlich, die Interaktion und die Sprache der Figuren muten wie geringfügig veränderte russische Dialoge an), kann andererseits bei dieser „niederschwellig-populären“ Darstellung des Alten Ägypten zugleich auch eine ,unterschwellige“ poetische Thematisierung von Herrschaft vermutet werden: Die in Bloks „historischem Bild“ dargestellte Sozialhierarchie gipfelt im Pharao Ramzes selbst, dessen Statthalter in Theben Psaru ist. Wenngleich sich Psaru unterwürfig vor Ramzes in den Staub wirft, geht vom Pharao auf den Statthalter ein Glanz über, wie sich in der Trauer um Psaru zeigt. In dieser Rangfolge der Despoten wird Ramzes als car' tituliert. Psaru bedankt sich für die überreichen Gaben mit einem Lied, dessen erste Verse („О царь, ты Горус меж людьми! Ты мне даешь бытие! Ты даешь бытие моему двойнику!“) Ramzes seinsspendende Kraft zuschreiben. Diese göttliche Fähigkeit legt im dritten Vers eine politische Lesart nahe, denn mit dvojnik ist wohl die symbolische Rolle des Statthalters bezeichnet, die Psaru dank Ramzes innehält. ${ }^{23}$ Das Verhältnis zwischen Ramses und Psaru lässt an die Idee des Gottesgnadentums denken, wobei der „begnadete“ Herrscher nicht Ramzes ist, sondern Psaru, der nur mit Bezug auf Ramzes seine Vollmachten hat. ${ }^{24}$ Wenngleich Blok in den Anmerkungen zu Ramzes die Gestalt des Pharaos von den anderen Figuren unterschieden haben will (letztere sind irdisch-komisch, Ramzes hingegen „fremd“, ,,abstrakt“, „,schön“, womit die Kontiguität zur symbolistischen Mythopoetik gewahrt bleibt), ist man aus heutiger Sicht geneigt, in Bloks „historischem Bild“ zugleich auch die Tendenz auszumachen, Theologie als Funktion der Politik

${ }^{22}$ Die Vorlage für diese „lebensnahe“ Darstellung alter Geschichte entnahm Blok populärhistorischen Arbeiten des französischen Ägyptologen Gaston Maspero (1846-1916) sowie dessen russischen Schülers B.A. Turaev (1868-1920).

${ }^{23}$ Erinnert sei hier an den Titel von Ernst Kantorowiczs berühmter Monographie The King's Two Bodies (1957).

24 Verführerisch erscheinen weiters Spekulationen über lautlich-semantische Relationen: Zwar ist Ramzes der car', Psaru als Name des Statthalters liegt phonetisch nahe, der Name weckt aber auch Assoziationen mit psu, dem Dativ von pes. Die letzte Replik von Ramzes lautet Sobake - sobač'ja smert'. Gemeint ist damit zwar der Tod des „Propheten“, den das Volk lyncht, weil ihm die Schuld am plötzlichen Tod von Psaru gegeben wird, eine kryptische Lesart könnte damit eine Anspielung auf den Tod des von „Gott“ begnadeten russischen Zaren sehen (im Plan zu Ramzes freilich gibt Blok selbst keinen Hinweis auf diesen hier hypostasierten zeitaktuellen Bezug). 
darzustellen, was zuletzt prominent - ebenso anhand von altägyptischer Geschichte - von Jan Assmann (etwa in 2002) vertreten wurde.

Evgenij Zamjatin konnte mit Ogni sv. Dominika (1920, gedruckt 1922), einem Drama aus der spanischen Inquisition, die Billigung durch die Kommission für „Istoričeskie kartiny“ erreichen, wenngleich die dargestellten Praktiken der Unterdrückung durch fanatische Katholiken auch die postrevolutionäre Gegenwart in Russland konnotieren ließen. Der Konflikt entsteht zwischen einem ungleichen Brüderpaar (der eine hat in den toleranten Niederlanden studiert, der andere schließt sich der Inquisition an) um eine Frau. Die Schergen der Inquisition rechtfertigen ihre Praktiken immer mit einem höheren Ziel, in ihrem religiösen Fanatismus wird aber niedriges irdisches Interesse sichtbar. So etwa bringt der Anhänger der Inquisition seinen Bruder aus Eifersucht auf den Scheiterhaufen, er wird jedoch von dessen Braut letztlich erstochen.

In Zamjatins Attila (1928) wird der Kampf zwischen den Hunnen und dem Römischen Reich als Streit zweier politischer Kulturen dargestellt: Die Römer halten viel auf ihre Hochkultur und ihre Kunstschätze, Attila macht aber darauf aufmerksam, dass diese elitär sei und auf Sklaverei beruhe. Die letztlich der Wildheit Attilas und den aufbegehrenden Sklaven nicht gewachsenen Vertreter des Imperiums müssen zur List greifen, so tötet etwa die Burgunderprinzessin Il'degonda Attila in der Hochzeitsnacht.

Die in Chlebnikovs Asparuch und Gumilevs Gondla erkennbare Poetisierung der Vergangenheit, die nicht nur an der variierten Versform, sondern vor allem an der komplexen Semantik der Figurenreden auszumachen ist, findet sich in extremer Form in Sergej Esenins Pugačev (1922), wo die Ereignisse des Kosakenaufstandes überlagert werden von Motivvariationen, die Naturbilder semantisch komplex verschachteln. Das dramatische Element reduziert sich auf die Opposition der Kosaken zur Moskauer Politik, die zum internen Konflikt der Kosaken wird und in Pugačevs Auslieferung an die Regierung endet. Esenin hat während der Arbeit an Pugačev intensive historische Studien betrieben, das historische Moment wird jedoch aufgehoben in Repliken, die lyrische Stimmungen der Figuren angesichts der herbstlichen südrussischen Steppe zum Ausdruck bringen.

Sofern man in den hier kurz skizzierten russischen historischen Dramen, die thematisch und gestalterisch höchst heterogen sind, eine Gemeinsamkeit ausmachen kann, besteht diese darin, dass einige markante Werke der russischen historischen Dramaturgie keine Stoffe der eigenen Geschichte behandeln, sondern Stoffe und Motive unterschiedlicher Traditionen und Epochen wählen. Schon dies kann als Indiz dafür gelten, dass das historische Drama in Russland nach 1900 in erster Linie nicht der Stärkung kollektiven Nationalbewusstseins in der Auseinandersetzung mit anderen Nationen diente, sondern in historischem Gewand Aspekte des Politischen thematisierte, die sich auf die russische Situation beziehen ließen, also Fragen des Zusammenlebens innerhalb eines Soziums betrafen. Die hier erwähnten Dramen aus der russischen Geschichte, Merežkovskijs Pavel I, die fiktive Familienchronik von 
Gnedič sowie Esenins Pugačev bestätigen ebenfalls diese Tendenz: Merežkovskij behandelt - wie viele Dramen des 19. Jahrhunderts, allerdings nicht anhand von Ivan IV., sondern von Pavel I. - die Fatalität der Autokratie, Gnedič den von der Politik affizierten byt der Aristokratie im 19. Jahrhundert, Pugačev kann als lyrische Darstellung der Vorstellungswelt der Kosaken gelten. Die um 1917 geschriebenen Dramen sind entweder mit dem Niedergang der Monarchie (Otravlennaja tunika, Attila) oder der Darstellung (un-)ethischen Handelns in der Politik (Gondla, Ogni svjatogo Dominika) befasst. Die politischen Konflikte haben meist keine ,internationale“ Dimension, sondern entstehen zwischen Gruppen ein und derselben Gesellschaft.

V. Nachdem sich die tschechische Nation im Lauf des 19. Jahrhunderts konsolidiert hatte und nach 1918 im Verein mit der slowakischen Staatsnation geworden war, setzte die tschechische Theaterhistorikerin und „Nationalfeministin“ Pavla Buzková rückblickend die Rolle des Dramas für die tschechische Kultur sehr hoch an. Vergleichbar sei die Rolle des Theaters für die tschechische Gesellschaft nur mit der Funktion der Tragödie für die griechische Polis:

České drama a osud obrozeného národa se skoro kryjí. Dýchají alespoň týmž dechem. [...] Proto odjakživa zaujímalo výjimečné postavení mezi dramaty evropskými. Jestliže vůbec kde, pak jistě v jeho krvavé vážnosti, která dbá jen stěžejních otázek života, doznívá staré drama řecké. (Buzková 1932: 27)

Es überrascht daher nicht, dass es in der tschechischen Tradition vergleichsweise wenige historische Dramen gibt, deren Stoff nicht der tschechischen Geschichte entnommen ist. ${ }^{25}$ Bestimmte Stoffkreise, die für die Dramatik des obrozeni charakteristisch waren, um die Kenntnis der Geschichte zu verbessern und ein entsprechendes Nationalbewusstsein zu schaffen (siehe dazu Mazáčovás Beitrag mit dem sprechenden Titel „Co je české, to je hezké“, Mazáčová 1997), wurden auch im 20. Jahrhundert fortgeführt. Um die oben beobachtete Verschiebung der Tendenz zwischen 1882 und 1903 (die eingefaltete „Erklärung“ für den dargestellten politischen Konflikt geht in Richtung des ,innenpolitischen Zwists“ und der Abkehr von der Aporie zwischen Politik und christlicher Ethik) weiter zu verfolgen, soll abschließend ein kurzer Überblick über vier Dramen aus dem Drahomíra-Václav-Stoffkreis gegeben werden. Alle vier Dramen - František Langers Erstling aus dem Jahre 1912, die Stücke von Jaroslav Durych 1925, Gabriela Preissová 1929 und Stanislav Lom 1935

${ }^{25}$ Nennenswert wäre im 19. Jahrhundert vor allem Vítězslav Hálek, der 1860 für Záviš z Falkenštejna immerhin als erster mit dem für die Hebung des historischen Nationaldramas ausgeschriebenen Fingerhut-Preis (Náprstkova cena) ausgezeichnet wurde: Hálek schrieb mit Král Vukašin (1862) ein Stück aus der serbischen Geschichte und stellte in Sergius Catilina (1863) die Komplexität des Catilina-Aufstandes dramatisch nach. Auch Emanuel Bozděchs Baron Goertz (1871) konnte mit der individualistischen Idee des Königsmordes (am schwedischen Hof) eine kritische Reaktion (u. a. von Jan Neruda, vgl. Vodička 1998: 362 ff.) hervorrufen. 
- tragen den Titel Svatý Václav, die Fabel der Stücke differiert jedoch stärker. So spitzt etwa Langer den Konflikt zwischen der leidenschaftlich-atavistischen Drahomíra und dem gleichsam von tolstojscher neprotivlenie zlu nasiliem geleiteten, doch in Notsituationen Waffengewalt erfolgreich einsetzenden Václav soweit zu, dass Boleslav nicht als Mörder, sondern bloß als Instrument Drahomíras erscheint und seine Herrschaft letztlich den dialektischen Ausgang dieses fundamentalen Konflikts verheißt. Auch Jaroslav Durych zeichnet Václav in der Politik erfolgreich, zum Brudermord kommt es vor allem aufgrund von Intrigen, die von heimtückischen Höflingen Boleslavs ausgeheckt werden und die Boleslav passiv duldet. Nach dem Mord liefert Boleslav die Schuldigen dem Volk aus. Die Václav-Figur Langers und Durychs ist politisch klug; Langer personifiziert Ideologien in den Hauptfiguren, Durych hingegen zeichnet detailliert interpersonelle Zwänge und Intrigen, die zum Mord führen. ${ }^{26}$ Der vor allem im 19. Jahrhundert deutlich spürbare nationale Gegensatz im Stoff der Václav-Legende bildet in diesen Dramen nur mehr den Hintergrund des Konflikts, der im Wesentlichen um die Darstellung politischer Konflikte und Ranküne kreist.

VI. Die zeitgebundenen Veränderungen des historischen Dramas sind am einfachsten wohl anhand des Wandels eines bestimmten Stoffkreises zu beobachten, doch macht auch die Abstraktion vom konkreten historischen Inhalt vorsichtige Beobachtungen möglich. So ist gerade in der russischen Literatur die Transformation zu lyrischeren und kürzeren Formen des Dramas erkenntlich, die meist mit „Enthistorisierung", verstärkten Anachronismen und mit polyvalenten historischen Bezügen einhergeht (etwa Asparuch, wo die Herodot-Erzählung in das frühe Mittelalter verlegt und von Chlebnikov selbst auf das gegenwärtige Russland bezogen wurde). Das tschechische historische Drama ist dabei vergleichsweise traditionell, die Veränderungen betreffen einerseits die Intrige, die verstärkt innertschechische Differenzen akzentuiert, andererseits verändert sich die Repräsentation von Geschichte: Entweder werden bestens bekannte Stoffe frei - mit größerer Entfernung von Quellen bzw. mit mehr fiktionalen Anteilen - interpretiert (etwa die Václav-Dramen von Langer und Durych) oder die Geschichte bildet den zeitlichen Hintergrund, vor welchem eine fiktionale Handlung unterschiedliche Aspekte menschlichen Handelns vorführt, die von der traditionellen Geschichtsschreibung nicht erfasst werden, wie z. B. psychologische und intersubjektive Momente, „Banalitäten“ des Alltags (die

${ }^{26}$ Gegenüber diesen beiden Stücken fallen die panegyrischen Darstellungen Václavs, die Preissová und Lom anlässlich der Václav-Milleniums-Feier verfasst haben, an politischem Gehalt deutlich ab, zeichnen sie doch Václav als perfekten Christen, der seinen egoistischen Feinden zum Opfer fällt. Ein Indiz für die konzeptuelle und dramaturgische Schwäche ist etwa der Umstand, dass Václavs ,transzendente Bedeutung“ (z. B. durch das Erscheinen von Engeln um Václav) unterstrichen wird (Einen informativen Überblick, der vor allem den Wandel der Figur des ,heiligen“ Václavs verfolgt und weniger die politischen Implikationen der Dramen beachtet, gibt Pulicarová 2005). 
historischen Dramen Dyks bzw. - im Russischen - Gnedičs). Derlei fiktionale Darstellungen vergangener Vorgänge muten paradoxerweiser historisch wahrhaftiger an als traditionelle Geschichtsdramen mit historischen Figuren.

\section{Abkürzungen}

Primärliteratur, tschechische:

Durych 1925: Jaroslav Durych, Svatý Václav - Kvas na Boleslavi, Praha

Dyk 1909:

Hilbert 1903:

Jirásek 1903:

Langer 1912:

Lom 1935:

Preissová 1929:

Vrchlický 1882:

Vrchlický 1889:

Vrchlický 1903:

Zeyer 1896: Viktor Dyk, Revoluční trilogie [I. Ranní ropucha; II. Figaro; III. Poražení], Praha 1922

Jaroslav Hilbert, Falkenštejn, Praha

Alois Jirásek, Jan Žižka, Sebrané spisy XXXVI, Praha 1922, 83-211

František Langer, Svatý Václav, Spisy Františka Langera, Hry I, Praha 2000, 5-106

Stanislav Lom, Svatý Václav. Tragická hra z českých dějin, Praha

Gabriela Preissová, Svatý Václav, Praha

Jaroslav Vrchlický, Drahomíra. České trilogie část první, Dramatické spisy Jaroslava Vrchlického sv. 1, Praha 1931, 1-103

Jaroslav Vrchlicky, Bratři. České trilogie část druhá, Dramatické spisy Jaroslava Vrchlického sv. 1, Praha 1931, 107-257

Jaroslav Vrchlicky, Knížata. České trilogie část třetí, Dramatické spisy Jaroslava Vrchlického sv. 1, Praha 1931, 261-396

Julius Zeyer, Neklan, Spisy Julia Zeyera sv. XXVII, Dramatická díla III, Praha 1947, 5-151

Primärliteratur, russische:

Blok 1921:

Chlebnikov 1911:

Esenin 1922:

Gnedič 1908:

Gnedič 1909:

Gumilev 1916:

Gumilev 1918:

Merežkovskij 1908:

Zamjatin 1922:

Zamjatin 1928:

Sekundärliteratur:

Ankersmit 2002:

Asmuth 1994:

Assmann 2002:
Aleksandr Blok, Ramzes, Polnoe sobranie sočinenij v 8-mi tomach, t. 4, Moskva 1964, 247-263

Velimir Chlebnikov, Asparuch, Sobranie sočinenij v 8-mi tomach, t. 4, Moskva 2003, 157-163

Sergej Esenin, Pugačev, Polnoe sobranie sočinenij v 7-mi tomach, t. 3, Moskva 1998, 7-52

Petr P. Gnedič, Cholopy, Sankt-Peterburg

Petr P. Gnedič, Dekabrist, Sankt-Peterburg

Nikolaj Gumilev, Gondla, Sobranie sočinenij v 4-ch tomach, t. 3, Washington 1966, 39-93

Nikolaj Gumilev, Otravlennaja tunika, Sobranie sočinenij v 4-ch tomach, t. 3, Washington 1966, 137-210

Dmitrij Merežkovskij: Pavel I. Drama dlja čtenija, Pavel I., Aleksandr I., Bol'naja Rossija, Moskva 1989, 25-150

Evgenij Zamjatin, Ogni sv. Dominika, Sočinenija, t. 2, München 1982, 243-281

Evgenij Zamjatin, Attila, Sočinenija, t. 2, München 1982, 389-448

Frank R. Ankersmit, Vom Nutzen und Nachteil der Literaturwissenschaft für die Geschichtstheorie, in: D. Fulda and S. S. Tschopp (Hrsg.), Literatur und Geschichte. Ein Kompendium zu ihrem Verhältnis von der Aufklärung bis zur Gegenwart, Berlin - New York, 12-37 Bernhard Asmuth, Einführung in die Dramenanalyse (= Sammlung Metzler), Stuttgart

Jan Assmann, Herrschaft und Heil. Politische Theologie in Altägypten, Israel und Europa, Frankfurt/M. 
Babičeva 1991:

Babičeva 1998:

Berwanger 2003:

Blok 1962:

Borová 1995:

Buzková 1932:

Černý 1969:

Duganov 1990:

Hegel 1986:

Hüttmann 2001:

Kantorowicz 1957:

Kindermann 1966:

Klosová 1977:

Lindenberger 1975:

Lotman 1996:

Lukács 1965:

Mazáčová 1997:

Nünning 1995:

Paul 1974:

Pavlovský 2004:

Pfister 2001:

Pulicarová 2005:
Ju. B. Babičeva, Istoričeskie dramy N. S. Gumileva „Gondla“ i „Otravlennaja tunika“, in: Russkaja dramaturgija i literaturnyj process, Sankt-Peterburg - Samara, 249-269

Ju. B. Babičeva, Metamorfozy russkoj istoričeskoj dramy v 10-ch godach XX veka, in: Neordinarnye formy russkoj dramy XX stoletija, Vologda, 5-18

Katrin Berwanger, Jaroslav Vrchlickýs Tschechische Trilogie (Ceská trilogie, 1882-1903). Der Geschichtsmythos als Maske, in: H. Schmid (Hrsg.), Kapitel zur Poetik. Vrchlický und der tschechische Symbolismus. Beiträge des Internationalen Bohemistischen Vrchlický-Symposiums an der Universität Potsdam 4.-7. Dezember 1997, München, $58-76$

Aleksandr Aleksandrovič Blok, Sobranie sočinenij v vos'mi tomach, t. VI, Moskva - Leningrad

Vladimíra Borová, Obraz Němců v české historické beletrii 18901900, in: Obraz druhého v historické perspektive, Praha, 11-39

Pavla Buzková, České drama, Praha

František Černý, České divadlo v předvečer buržoazně demokratické revoluce a za revoluce (1834-1848), in: F. Černý (Hrsg.), Dějiny českého divadla II, Praha, 198-357

Rudol'f Valentinovič Duganov, Velimir Chlebnikov. Priroda tvorčestva, Moskva

Georg Wilhelm Friedrich Hegel, Vorlesungen über die Ästhetik I, Frankfurt/M.

Andrea Hüttmann, Die Ästhetik der Geschichte. Das zeitgenössische historische Drama Spaniens im Spannungsfeld zwischen Sinn und Spiel (= Mainzer Forschungen zu Drama und Theater 25), Tübingen Basel

Ernst Kantorowicz, The King's Two Bodies. A Study in Medieval Political Theology, Princeton

Heinz Kindermann, Theatergeschichte Europas. Band I. Das Theater der Antike und des Mittelalters, Salzburg

Ljuba Klosová, Pozdní romantismus na profesionálním divadle v období státoprávních bojů a politické stagnace českého měšt'anstva (1862-1886), in: F. Černý L. Klosová (Hrsg.), Dějiny českého divadla III. Ċinohra 1848-1918, Praha, 45-175

Herbert Lindenberger, Historical Drama. The Relation of Literature and Reality, Chicago - London

Ju. M. Lotman, Kommentarij [k Borisu Godunovu. Tragedija], in: Puškin, A. S., Boris Godunov. Tragedija. Russkaja klassika s kommentarijami, Sankt-Peterburg, 117-366

Georg Lukács, Der historische Roman (= Georg Lukács Werke 6), Neuwied - Berlin

Barbara Mazáčová, Co je české, to je hezké, Divadelní revue 8, 2, 311

Ansgar Nünning, Von historischer Fiktion zu historiographischer Metafiktion. Band 1. Theorie, Typologie und Poetik des historischen Romans (= Literatur - Imagination - Realität. Anglistische, germanistische, romanistische Studien 11), Trier

Ulrike Paul, Vom Geschichtsdrama zur politischen Diskussion. Über die Desintegration von Individuum und Geschichte bei Georg Büchner und Peter Weiss, München

Petr Pavlovský, Historické drama, in: Základní pojmy divadla. Teatrologický slovník, Praha, 114-115

Manfred Pfister, Das Drama. Theorie und Analyse, München

Irena Pulicarová, Svatý Václav jako dramatická hrdina, Teologie \& Společnost $6,5-10$ 
Rak 1994:

Řezníková 2004:

Schamschula 1996:

Sečkarev 1966:

Szondi 1978:

Timenčik 1992:

Virolajnen 1987:

Vlček 2006:

Vodička 1998:

White 1973:

Peter Deutschmann

Institut für Slawistik der Karl-Franzens-Universität Graz

Merangasse 70, $8010 \mathrm{Graz}$, Österreich

peter.deutschmann@uni-graz.at ny Praha I, Frankfurt/M., 11-148 1800-1917, Moskva, 53-57 1917 g.), Leningrad, 309-335 415
Jiří Rak, Bývali Čechové. České historické myty a stereotypy, Jinoča-

Lenka Rezníková, Moderna \& Historismus. Historické reprezentace v proměnách literatury na přelomu devatenáctého a dvacátého století,

Walter Schamschula, Geschichte der tschechischen Literatur. Bd II. Von der Romantik bis zum Ersten Weltkrieg (= Bausteine zur Slavischen Philologie und Kulturgeschichte. Reihe A. Slavistische Forschungen NF 14), Köln - Weimar - Wien

V. M. Sečkarev, Gumilev-dramaturg. Vstupitel'naja stat'ja, in: G. P. Struve and B. A. Fillipov (Hrsg.), Nikolaj Gumilev: Sobranie sočinenij v četyrech tomach, Washington, III-XXXVII

Peter Szondi, Theorie des modernen Dramas, in: P. Szondi, Schriften

R. D. Timenčik, Nikolaj Stepanovič Gumilev, in: Russkie pisateli

M. N. Virolajnen, Istoričeskaja dramaturgija 1850-1870-ch godov, in: Istorija russkoj dramaturgii (vtoraja polovina XIX - načalo XXv. do

Radomír Vlček, Panslavismus či rusofilství? Pět tezí k otázce reflexe slovanství a panslavismu českou společností 19. století, in: „Slavme slavně slávu Slávóv slavných“. Slovanství a česká kultura 19. století. Sborník př́spěvků z 25. ročníku symposia k problematice 19. století, Plzeň 24.-26. února 2005, Praha, 9-20

Felix Vodička, Koncepce modernosti v Nerudově literární kritice, in: F. Vodička, Struktura vývoje. Studie literárněhistorické, Praha, 347-

Hayden White, Meta-History. The historical imagination in nineteenth-century Europe, Baltimore - London 